
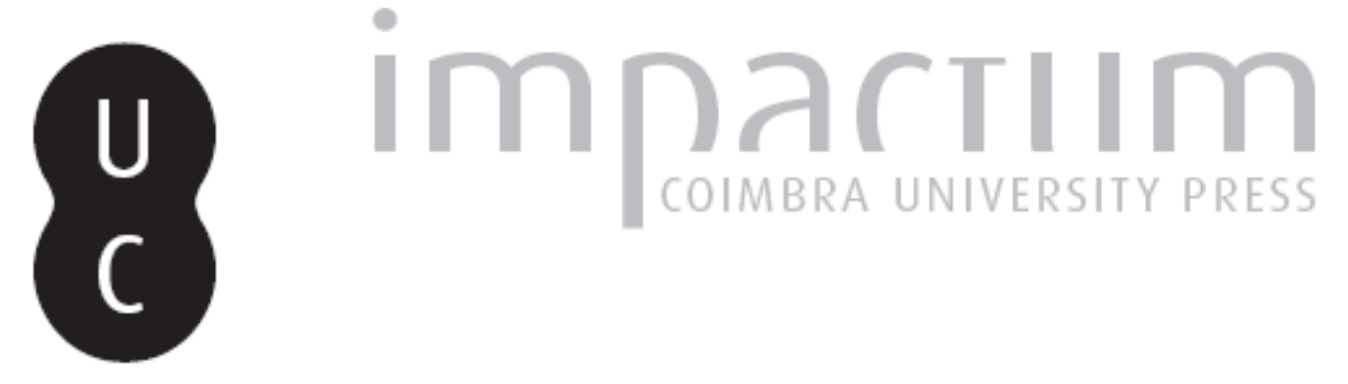

\title{
Formas imagéticas e formas discursivas
}

\author{
Autor(es): Braga, Joaquim
}
Publicado por: Faculdade de Letras da Universidade de Coimbra, Instituto de Estudos Filosóficos

URL persistente:

URI:http://hdl.handle.net/10316.2/33339

DOI:

DOI:http://dx.doi.org/10.14195/0872-0851_37_7

Accessed : $\quad$ 26-Apr-2023 01:37:46

A navegação consulta e descarregamento dos títulos inseridos nas Bibliotecas Digitais UC Digitalis, UC Pombalina e UC Impactum, pressupõem a aceitação plena e sem reservas dos Termos e Condições de Uso destas Bibliotecas Digitais, disponíveis em https://digitalis.uc.pt/pt-pt/termos.

Conforme exposto nos referidos Termos e Condições de Uso, o descarregamento de títulos de acesso restrito requer uma licença válida de autorização devendo o utilizador aceder ao(s) documento(s) a partir de um endereço de IP da instituição detentora da supramencionada licença.

Ao utilizador é apenas permitido o descarregamento para uso pessoal, pelo que o emprego do(s) título(s) descarregado(s) para outro fim, designadamente comercial, carece de autorização do respetivo autor ou editor da obra.

Na medida em que todas as obras da UC Digitalis se encontram protegidas pelo Código do Direito de Autor e Direitos Conexos e demais legislação aplicável, toda a cópia, parcial ou total, deste documento, nos casos em que é legalmente admitida, deverá conter ou fazer-se acompanhar por este aviso.

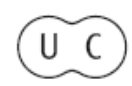




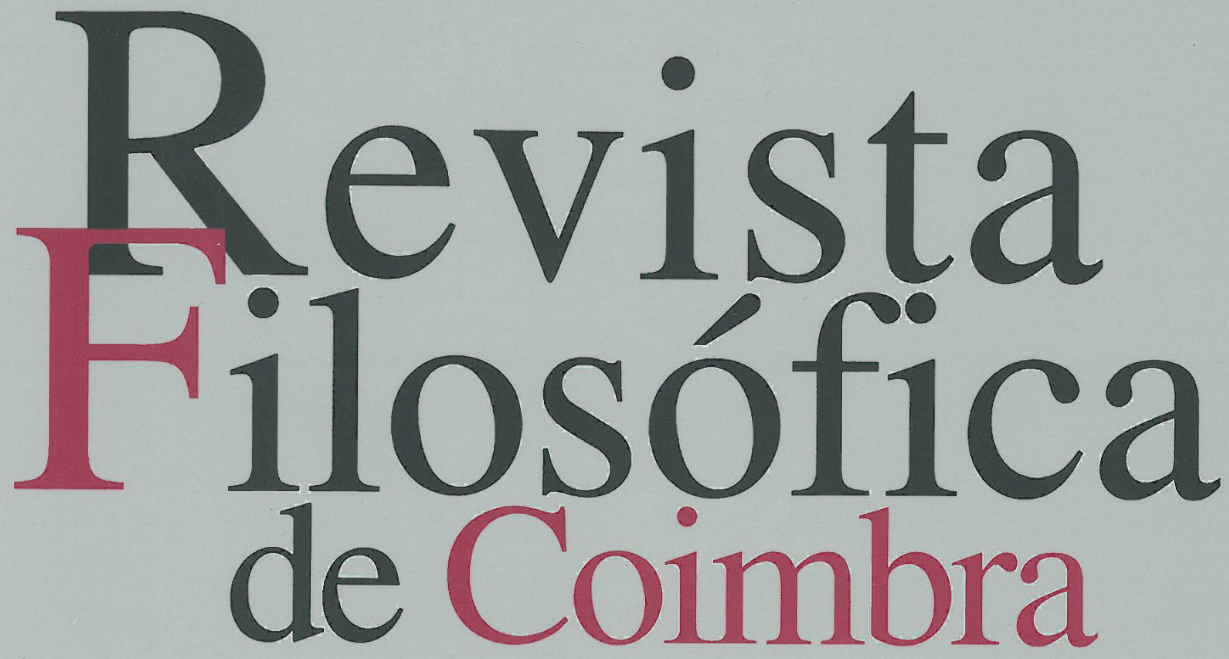

vol.19|n. $.37 \mid 2010$

Maria Luísa Portocarrero Mário Santiago de Carvalho Alexandre Franco de Sá Luís António Umbelino Luís G. Soto José Filipe Silva Joaquim Braga Maria da Conceição Camps Pedro Miguel Panarra Immanuel Kant 


\title{
FORMAS IMAGÉTICAS E FORMAS DISCURSIVAS
}

\author{
JOAQUIM BRAGA*
}

Resumo: A redução do cultural ao visual parece hoje sustentar uma crítica negativa da imagem. Crítica essa que, ancorada na ideia de uma pretensa impotência da palavra perante a ascensão das formas imagéticas, tende a assumir, muitas das vezes, um carácter iconofóbico. Dois dos fundamentos que servem comummente para justificar tal primado medial das formas imagéticas sobre as formas discursivas podem ser enumerados do seguinte modo: (1) a medialidade imagética é marcada por um perfil transcultural invariável, não dependendo, por isso, da configuração cultural dos actos perceptivos; (2) as estruturas visuais que tornam possível essa invariabilidade possuem uma autonomia em relação às estruturas linguísticas das formas discursivas. A reflexão que aqui se apresenta tem como objectivo principal questionar o conteúdo destes dois fundamentos, apontando, por outro lado, para modelos de interpretação alternativos capazes de dar resposta à relação cultural entre formas imagéticas e formas discursivas.

Palavras-chave: formas imagéticas, formas discursivas, articulação, materialidade, configuração.

Abstract: The interpretation of culture only by visual forms seems to lead, today, to a negative evaluation of images. This negative evaluation, based on words' loss of power in comparison to ascendancy of pictorial forms, usually undertakes an iconophobic character. Two of the reasons that commonly justify the medial primacy of pictorial over discursive forms can be expressed by: (1) visual mediality is characterised by an unchangeable transcultural dimension

* Bolseiro da Fundação para a Ciência e a Tecnologia, Humboldt-Universität zu Berlin, Institut für Philosophie, E-mail: joaquim.braga@yahoo.com. 
and is independent of cultural influence on human perception; (2) visual structures that enable the unchangeable transcultural dimension of pictures are self-governed in relation to linguistic structures of discursive forms. The major aim of this paper is to enquire the content of the arguments described above. Another aim is to purpose alternative arguments that are able to connect pictorial to discursive forms, by a cultural point of view.

Keywords: pictorial forms, discursive forms, articulation, materiality, configuration.

\section{Introdução}

A relação entre imagem e cultura tende a ser pensada a partir de um pressuposto ontológico que opõe o visual ao discursivo. Porém, se é certo que um e outro possuem estruturas específicas, também é certo que uma diferenciação depende, em rigor, do modo como ambos são configurados culturalmente. Podemos ver já nisso, na diferença dada pelas estruturas das formas de mediação, o despontar da complexidade social, da diversidade cultural e, ao mesmo tempo, da subjectividade do ser humano. A reflexão sobre a questão da alteridade passa, nessa exacta medida, pela inclusão da questão da medialidade como ponto de partida fundamental. Inclusão essa que não tem sido ignorada pela filosofia. Pelo contrário. A medialidade tornou-se, actualmente, numa das temáticas mais inquiridas, acentuando-se, com isso, uma verdadeira transformação dos objectos e métodos da própria filosofia.

A importância que a imagem tem vindo a despertar nos estudos das ciências da cultura é, em grande parte, uma consequência dessa transformação. O pictorial turn ${ }^{1}$ e o iconic turn ${ }^{2}$ - dois dos paradigmas que ganharam maior destaque na reflexão sobre a medialidade imagética designam uma mudança cultural provocada pela vasta oferta de conteúdos visuais mediados pelas novas tecnologias de informação. Por outro lado, designam também uma mudança paradigmática no seio das ciências da cultura, quer em relação ao abandono de uma concepção exclusivamente logocêntrica do objecto cultural quer na afirmação do primado da imagem como objecto de estudo - o que seria, neste segundo sentido do turn, uma resposta ao linguistic turn popularizado por Richard Rorty. ${ }^{3}$ Se para Rorty,

${ }^{1}$ Mitchell, W. J. T., The pictorial turn, in: Picture Theory. Essays on verbal and visual representation, Chicago \& London, Chicago University Press, 1994, pp. 11-34.

${ }^{2}$ Boehm, G., Die Wiederkehr der Bilder, in: Was ist ein Bild?, Hrsg. von Gottfried Boehm, München, Wilhelm Fink Verlag, 1994, pp. 11-38.

${ }^{3}$ Rorty, R. M., The linguistic turn: Recent essays in philosophical method, Chicago \& London, Chicago University Press, 1967. 
as ciências da linguagem, como a linguística, a semiótica e a retórica, formam uma língua franca para a interpretação das formas culturais, o principal escopo de uma mudança paradigmática estaria em privilegiar não apenas a textualidade e discursividade dos modelos linguísticos, mas também as próprias lógicas visuais inerentes aos sistemas simbólicos não-linguísticos. A história da arte, segundo John Mitchell e outros autores do Visual Studies,${ }^{4}$ não consegue responder às exigências de um primado do visual nas nossas culturas. Para Mitchell esta é uma necessidade sobretudo histórico-cultural, dado a história da cultura estar, no seu entender, já marcada por uma tensão entre símbolos linguísticos e símbolos picturais. ${ }^{5}$

A questão que aqui se coloca - e essa é a nossa questão fundamental - é saber até que ponto tal relação cultural entre formas imagéticas e formas discursivas corresponde a um pretenso primado do visual. Ou sob forma de pergunta: Deixar-se-á o imagético reduzir às categorias do visual?

\section{Imagem, fenómeno, signo}

Ora, a tensão entre formas imagéticas e formas discursivas que Mitchell assinala não tem sido destacada nas reflexões sobre a filosofia da imagem, pois as atenções têm vindo a ser centradas principalmente no estatuto ontológico da imagem. A questão fundamental que tem orientado o debate pode ser enunciada da seguinte forma: o que é que distingue as formas imagéticas das formas discursivas? - ou, como sugere o título da obra editada por Gottfried Boehm, Was ist ein Bild? (O que é uma imagem?). Como respostas a esta questão, destacam-se duas concepções teóricas divergentes: (1) a concepção fenomenológica que, na sua génese husserliana, remete a imagem para a esfera de uma visualidade pura cuja natureza não se deixa subtrair aos processos de significação; e (2) a concepção semiótica que, ao aplicar os mesmos métodos utilizados na análise da linguagem, concebe a imagem unicamente a partir das suas estruturas sígnicas.

\footnotetext{
${ }^{4}$ Para uma introdução às temáticas do Visual Studies e ao pensamento de alguns dos seus autores principais, vide Dikovitskaya, Margaret, Visual Culture: The study of the visual after the cultural turn, Cambridge/Massachusetts, MIT Press, 2006.

${ }^{5}$ Mitchell, W. J. T., Iconology: image, text, ideology, Chicago \& London, Chicago University Press, 1986, p. 43.
} 
Comecemos por introduzir na nossa reflexão algumas das linhas mestras que tecem as diferenças entre a ideia de uma "imagem-signo" e a ideia de uma "imagem-fenómeno".

\subsection{A imagem-fenómeno: o primado da similaridade}

Para a concepção fenomenológica, a natureza da imagem revela-se sobretudo com o seu carácter visual presentativo. Ao contrário do seu carácter representativo, a visualidade que a presença da imagem transporta não é redutível às funções sígnicas da linguagem, mas antes cria uma incompatibilidade entre signo e percepção, imaginação e significação que não obedece a qualquer critério simbólico representacional. E nesse sentido que Lambert Wiesing, um dos maiores defensores da imagem-fenómeno, pode afirmar que a imagem torna visível algo - real ou imaginário - que de outra maneira não poderia ser visto; afirmação que remete, por extensão, para a tradicional dicotomia entre "presença" e "ausência", ou seja, «cada imagem revela uma antinomia visível entre presença e ausência». 6 Algo que é tornado presente é algo que não é representado, mas antes presentificado. Daí também a inevitável conclusão a que Wiesing chega: a imagem não precisa de ser signo (imagem-signo) para poder ser imagem, já que, antes de poder ser signo, tem de mostrar algo que possa ser utilizado como signo. ${ }^{7}$

A génese desta formulação proposta por Wiesing encontra-se na filosofia de Edmund Husserl. O filósofo dividiu a imagem-fenómeno em três elementos estruturantes: o suporte material da imagem (Bildding); o objecto pictórico que aparece na superfície física da imagem (Bildobjekt); e, por fim, o objecto representado pelo objecto pictórico (Bildsujet). ${ }^{8}$ Não é a presença do Bildobjekt, mas antes, como refere Lambert Wiesing, a "presença artificial"9 do Bildsujet através do Bildobjekt que proporciona o carácter intencional da representação e a sua natureza imagética. A representação é, nessa exacta medida, vista a partir de uma pretensa causalidade natural entre "presença" e "ausência", objecto representante

${ }^{6}$ Wiesing, Lambert, Die Sichtbarkeit des Bildes. Geschichte und Perspektiven der formalen Ästhetik, Frankfurt/New York, Campus Verlag, 2008, p. 15. Esta antinomia, porém, não faz jus àqueles contextos de exibição em que a imagem mostra algo que não está ausente, como por exemplo, quando $x$ (= imagem do orador de uma conferência) reforça ou ilustra simultaneamente a presença física de $y$ (=o orador).

${ }^{7}$ Idem, Artifizielle Präsenz. Studien zur Philosophie des Bildes, Frankfurt am Main, Suhrkamp Verlag, 2005, p. 55.

${ }^{8}$ Husserl, Edmund, Phantasie und Bildbewusstsein, Hrsg. von Eduard Marbach, Text nach Husserliana, Band XXIII, Hamburg, Felix Meiner Verlag, 2006, p. 21. 
e objecto representado. $\mathrm{O}$ objecto-imagem tem a funcao de mostrar, de tornar presente - presentificar - o objecto ausente que o sujeito-imagem evoca. $\mathrm{E}$ é por causa dessa evocação que, segundo Husserl, a imagem vai entrar em conflito (Widerstreit) com o momento actual em que é percepcionada, já que algo ausente é percepcionado como algo presente na imagem. ${ }^{10} \mathrm{Da}$ impossibilidade de a imagem poder importar todas as características configuracionais dos objectos que mostra - se a importação fosse total, a imagem redundaria em ilusão -, surge o "conflito" ontológico entre representação e realidade e, com este, a desilusão de uma osmose perfeita.

A Epoché fenomenológica, embora sendo marcada por uma redução eidética, não pretende, porém, negar o carácter cultural da imagem. Husserl reconhece o seu sentido simbólico. ${ }^{11}$ No entanto, e partindo da distinção entre conhecimento simbólico e conhecimento intuitivo proposta por Gottfried Wilhelm Leibniz, ${ }^{12}$ Husserl vai conceber a imagem a partir de uma «consciência de imagem intuitiva» que, ao contrário das representações simbólicas, é marcada por uma visualidade imanente: ${ }^{13}$ entre imagem e objecto representado há uma adequação imediata (adaequatio imaginis ad rem); adequação essa que é típica do conhecimento intuitivo - como já Leibniz defendia - e que faz com que a imagem, ainda desprovida de atributos sígnicos, se mostre de forma absoluta, isto é, na sua visualidade pura.

Deste modo, a imagem, ao invés do signo (Zeichen), mantém uma relação de similaridade (Ähnlichkeit) com o objecto representado. Partindo da ideia de que há uma similaridade entre os dois, de que uma imagem só é verdadeiramente imagem quando acontece uma congruência (Deckung) entre objecto representante e objecto representado ${ }^{14}$ - o que excluiria as

${ }_{9}^{9}$ Wiesing, Lambert, op. cit., p. 31.

${ }^{10}$ Husserl, Edmund, op. cit., p. 49.

11 Idem, Phänomenologische Psychologie, Hrsg. von Dieter Lohmar, Text nach Husserliana, Band IX, Hamburg, Felix Meiner Verlag, 2003, pp. 110-118.

${ }^{12}$ Leibniz, G. W., Meditationes de Cognitione, Veritate et Ideis - Betrachtungen über die Erkenntnis, die Wahrheit und die Ideen, in: Philosophische Schriften, Band I, Kleine Schriften zur Metaphysik, Hrsg. und Übers. von Hans Heinz Holz, Darmstadt, Wissenschaftliche Buchgesellschaft, 1985, pp. 25-47, p. 33. Esta linha de demarcação entre "intuitivo" e "simbólico" não é seguida por Immanuel Kant. Para o filósofo de Königsberg, a esfera do simbólico - conhecimento mediado por analogia - é, juntamente com as formas esquemáticas mediadas por demonstração, uma parte integrante do conhecimento intuitivo. Kant, Immanuel, Kritik der Urteilskraft, Hrsg. von Wilhelm Weischedel, Frankfurt am Main, Suhrkamp Verlag, 1974, § 59, pp. 294-299.

${ }^{13}$ Husserl, Edmund, Phantasie und Bildbewusstsein, p. 37.

14 Ibidem, p. 33. 
formas imagéticas abstractas -, Husserl relega a consciência de imagem para a esfera de um processo ontológico de negação do real. A imagem, dado o conflito que vem provocar com o presente, acaba por se transformar em uma presença desprovida de ser. O objecto representado - objecto ausente - determina, nessa exacta medida, a ausência ontológica, o nada, o fictício que se presentifica artificialmente. Se não houver nenhuma semelhança entre imagem e objecto, segundo a conclusão de Husserl nas Logische Untersuchungen, não estamos perante uma imagem. ${ }^{15}$ Tal relação de similaridade permanece como uma relação análoga à das "imagens naturais", visto que a superfície física da imagem, qual fenómeno óptico, tem um carácter de projecção que permite a intuição do objecto representado através do objecto pictórico. Daí que, como aliás defende Eugen Fink, as "imagens naturais" tenham de ser sempre um ponto de partida fenomenológico para a análise da visualidade pura das "imagens artificiais". ${ }^{16}$

\subsection{A imagem-signo: o primado da convencionalidade}

Este primeiro momento da mediação - momento originário, assim concebido -, em que se forma a identidade causal entre representante e representado reclamada pelas teorias da semelhança, é também assinalado por Charles Sanders Peirce como uma característica essencial dos signos icónicos, já que estes pressupõem sempre uma coexistência mental simultânea do representante e do representado. ${ }^{17}$ Não se trata aqui, como adverte Umberto Eco, de uma mera imitação dos atributos hápticos do objecto designado - que tanto pode ser visual como acústico ou táctil -,

${ }^{15}$ Husserl, Edmund, Elemente einer phänomenologischen Aufklärung der Erkenntnis II/2, in: Logische Untersuchungen, Tübingen, Max Niemeyer Verlag, 1993, p. 54. A mesma ideia é defendida por Wittgenstein, Ludwig, Tractatus logico-philosophicus Logisch-philosophische Abhandlung, Frankfurt am Main, Suhrkamp Verlag, 2003, 2.16-2.161 , p. 15.

${ }^{16}$ Fink, Eugen, Studien zur Phänomenologie 1930-1939, Den Haag, Martinus Nijhoff, 1966, p. 73. Esta ideia é, contudo, negada por Lambert Wiesing. Para o filósofo da imagem, as características visuais de um medium não podem ser comparadas às dos fenómenos físicos (naturais ou artificiais), visto que o medium torna visível algo que não depende da sua natureza material durante os processos de mediação, algo que, ao contrário das ditas "imagens naturais" - designação esta que, em rigor, tende a obscurecer a questão da medialidade -, não depende de uma explicação baseada em leis da física. Wiesing, Lambert, op. cit., pp. 159-161.

17 Peirce, Charles S., Semiotische Schriften, Band I, Hrsg. und übers. von Christian Kloese und Helmut Pape, Frankfurt am Main, Suhrkamp Verlag, 1986, p. 226. 
mas antes de uma adequação mental entre as «propriedades configuracionais do objecto que é representado pelo ícone» e as formas materiais que configuram a iconicidade do signo. ${ }^{18}$

Apesar de a semiótica peirceana contemplar a questão da similaridade, os argumentos que tecem as novas correntes da semiótica têm vindo a destacar mais a compatibilidade entre signo e percepção, independentemente do grau de iconicidade entre representante e representado. A semiótica encontra nas estruturas sígnicas da imagem a possibilidade de esta ser interpretada de forma análoga à das estruturas sígnicas da linguagem. Se a produção e a recepção de uma imagem fazem parte de «um processo de comunicação visual», então isso significa também que a imagem «comunica algo». ${ }^{19}$ Este "comunicar algo" passa a constituir a mensagem visual da imagem, sendo, por isso, o seu carácter sígnico aquele que proporciona a mediação da mensagem.

Esta argumentação remete-nos para as teorias da convencionalidade. Nelson Goodman, um dos autores que mais tem inspirado os defensores da imagem-signo, concebe a relação entre imagem e representação a partir dos sistemas de referência convencionais; sendo, por sua vez, as modalidades de denotação - presentes em imagens que denotam objectos ou acontecimentos com uma extensão real, como por exemplo, a fotografia de uma pessoa - as formas de simbolização que mais se manifestam nas representações imagéticas. A teoria da imagem em Goodman é suportada por uma gramática visual da imagem. A referencialidade das formas imagéticas é o critério que ele utiliza para pensar a relação entre símbolo e simbolizado. ${ }^{20}$ «A denotação é o cerne da representação e não depende de similaridade.» ${ }^{21}$ Daí que a denotação seja dada por convenção e não por uma causalidade natural entre imagem e objecto representado.

${ }^{18}$ Eco, Umberto, Zeichen. Einführung in einen Begriff und seine Geschichte, Übers. von Günter Memmert, Frankfurt am Main, Suhrkamp Verlag, 1977,139-140.

${ }^{19}$ Nöth, Winfried, Warum Bilder Zeichen sind, In: Bild-Zeichen. Perspektiven einer Wissenschaft vom Bild, Hrsg. von Stefan Majetschak, München, Wilhelm Fink Verlag, 2005, pp. 49-61, p. 60.

20 Goodman, Nelson, Vom Denken und anderen Dingen, Übers. von Bernd Philippi, Frankfurt am Main, Suhrkamp Verlag, 1987, p. 86.

${ }^{21}$ Idem, Sprachen der Kunst. Entwurf einer Symboltheorie, Übers. von Bernd Philippi, Frankfurt am Main, Suhrkamp Verlag, 1998, p. 17. Convém realçar aqui que, segundo Goodman, as imagens fictícias - como por exemplo, a imagem que representa um unicórnio - não têm um carácter denotacional. A denotação implica sempre um referente com existência factual. Esta regra encontra-se já na semiótica de Morris, Charles W., Grundlagen der Zeichentheorie, Übers. von Roland Posner, Frankfurt am Main, Fischer Verlag, 1988, p. 47. 
A regra da convenção aplica-se também ao estatuto ontológico da imagem como obra de arte. Goodman prefere questionar a arte não em função da sua idealidade - o que é arte? -, mas antes em função dos contextos de exibição das obras - quando é arte?. Assim, segundo o filósofo americano, uma obra só é verdadeiramente obra de arte quando está inserida dentro de um espaço artístico convencional (museu, galeria). ${ }^{22}$ A materialidade de uma imagem (ou de uma estátua) só se dá como obra e como símbolo se for contextualizada dentro de um espaço reservado a objectos artísticos. Na linguagem de Goodman, esta ideia teria a seguinte tradução: o processo normal de denotação é invertido; o estatuto da imagem é "exemplificado" pela referência dada pelo contexto.

No entanto, e ainda que Goodman aplique os modelos da semiótica da linguagem aos da semiótica da imagem, não se encontra nas suas teses nucleares uma alusão clara a momentos em que as próprias formas discursivas articulam processos de mediação imagéticos. E a razão principal que pode justificar este facto encontra-se na distinção basilar que Goodman estabelece entre formas linguísticas e formas não-linguísticas. A imagem é-nos antes descrita como símbolo que, mantendo uma independência em relação às estruturas sígnicas da linguagem, não possui qualquer articulabilidade, já que os sistemas de representação imagéticos são marcados por uma «densidade» simbólica que lhes não permite ter «disjuntividade» sintáctica e semântica. ${ }^{23} \mathrm{O}$ conceito de "articulação" é, nesta medida, utilizado por Goodman apenas como sinónimo da "diferenciação" que caracteriza as estruturas gramaticais da linguagem falada e escrita, não contemplando, por isso, a ambiguidade semântica e a densidade pictórica da imagem.

\section{Percepção, articulação, cultura}

Com efeito, este esgrimir de posições entre os defensores da "imagem-signo" e da "imagem-fenómeno" não tem deixado lugar de reflexão para a relação entre formas imagéticas e formas discursivas. E as causas que conduzem a isso parecem ser aqui bastante claras: a concepção de "imagem-signo", tal como tem sido proposta pela semiótica, não privilegia o papel da percepção nem o substrato sensível da imagem nos processos de mediação - a percepção, estando ligada a sistemas de referência convencionais, não cria qualquer obstáculo epistemológico à mediação

22 Goodman, Nelson, Weisen der Welterzeugung, Übers. von Max Looser, Frankfurt am Main, Suhrkamp Verlag, 1990, p. 87.

${ }^{23}$ Idem, Sprachen der Kunst, pp. 209-210. 
imagética, isto é, a imagem é um medium transparente; a concepção de "imagem-fenómeno", pelo contrário, tem vindo a acentuar a autonomia do visual em detrimento dos processos de mediação sígnicos - a mediação, tendo a função de tornar algo visível, deixa-se submeter à intencionalidade que marca os actos perceptivos puros.

Desde Ernst Cassirer que sabemos que a imagem é um signo sensível cuja materialidade lhe permite ser objecto cultural e, nessa exacta medida, símbolo. ${ }^{24}$ E Erwin Panofsky, seguindo as reflexões propostas por Cassirer, vai designar a "perspectiva" como forma simbólica, abandonando, com isso, a ideia de um olhar neutro e de uma percepção pura desprovidos de articulação cultural. ${ }^{25}$ A nossa percepção, sendo articulada - e, com isso, sujeita à variabilidade cultural -, não apreende os fenómenos como matéria pura, mas é já marcada por estruturas de compreensão colectivas, por formas culturais que tecem a sua «pregnância simbólica» (symbolische Prägnanz) ${ }^{26}$, como diria Cassirer. Por outro lado, essa articulação só é possível graças às estruturas sígnicas internas da imagem. A estrutura sígnica da imagem começa por ser estrutura interna, já que os elementos sensíveis que a definem como artefacto - linhas, pontos, cores etc. - obedecem a uma relação entre si dentro do espaço da

24 Cassirer, Ernst, Philosophie der symbolischen Formen. Teil 2. Das mythische Denken, Darmstadt, Wissenschaftliche Buchgesellschaft, 1994, pp. 279-311; Idem, Wesen und Wirkung des Symbolbegriffs, Darmstadt, Wissenschaftliche Buchgesellschaft, 1994, pp. 187-191. Hans Belting vai seguir a mesma ideia traçada por Cassirer. Para Belting, a imagem é uma «unidade simbólica» (symbolische Einheit) que resulta do facto de o ser humano ter a capacidade de isolar e articular a sua actividade visual. Daí que a percepção imagética - «um acto de animação» através do qual a imagem ganha a sua dinâmica sensível - seja «uma acção simbólica» que varia de cultura para cultura. A imagem como "acção simbólica" está, nesse sentido, ligada à mediação do corpo. Na opinião de Belting, o acto perceptivo imagético, sendo um acto dado num e por um corpo, faz com que o corpo seja o verdadeiro «lugar das imagens» (Ort der Bilder). Belting, Hans, Bild-Anthropologie, München, Wilhelm Fink Verlag, 3. Auflage, 2006, pp. 11-13.

25 Panofsky, Erwin, Die Perspektive als „symbolische Form”, in: Aufsätze zu Grundfragen der Kunstwissenschaft, Hrsg. von Hariolf Oberer und Egon Verheyen, Berlin, Verlag Bruno Hessling, 1974, pp. 99-167, p. 108.

${ }^{26}$ Cassirer, Ernst, Philosophie der symbolischen Formen. Teil 3. Phänomenologie der Erkenntnis, Darmstadt, Wissenschaftliche Buchgesellschaft, 1994, pp. 222-237. O conceito de "pregnância simbólica" refere-se, essencialmente, ao sentido não intuitivo que acompanha e estrutura simultaneamente o modo como as nossas vivências perceptuais sensíveis são articuladas. É através dessa articulação que os fenómenos sensíveis são configurados e diferenciados, tornando-se assim possível que as formas simbólicas míticas, religiosas, artísticas, científicas - possam ser compreendidas e diferenciadas quando materialmente fixadas em formas sensíveis. 
superfície pictórica. ${ }^{27}$ Sem esta coerência interna - como, aliás, tende a acontecer em certos casos patológicos de agnosia visual - ser-nos-ia impossível de configurar qualquer motivo imagético (figurativo ou abstracto).

Ultrapassar a incompatibilidade entre estruturas sígnicas e estruturas sensíveis da imagem é, por um lado, pôr em causa a própria questão da similaridade entre imagem e objecto, e, por outro, questionar os modos como imagem e palavra simbolizam os seus conteúdos. A distinção entre formas imagéticas e formas discursivas encerra, na sua fundamentação teórica, uma dicotomização entre cultura e natureza, mimesis e convenção. Associadas à visualidade da imagem, encontramos quer uma pretensa adequação natural entre visual e visível quer uma congruência entre os objectos da representação - objecto representado e objecto representante. Adequação e congruência são, nessa exacta medida, dois momentos capitais que estruturam o conceito de imagem como signo natural, mais concretamente, como fenómeno desprovido de articulação simbólica. Daí resulta uma caracterização da imagem sustentada na ideia de transparência, como se pode, por exemplo, deduzir da distinção entre "belo" e "sublime" proposta por Edmund Burke: o sublime, porque inerente à dor e à obscuridade, só se manifesta através da mediação das formas discursivas na sua expressão propriamente lírica; o belo, porque inerente ao prazer e à transparência, torna-se visível através da correspondência mimética desencadeada pelas formas imagéticas. ${ }^{28}$

Se na distinção proposta por Burke há uma caracteriologia da imagem assente numa lógica hedonista - um legado, em parte, transmitido pela visão da imagem associada ao célebre mito de Narciso -, já em formulações posteriores tal caracteriologia tende a ganhar um perfil essencialmente naturalista, agudizando-se, com isso, a distância intransponível entre imagem (natureza) e palavra (cultura). As teorias da semelhança vieram dar relevância a essa distância, procurando interpretar a imagem segundo uma lógica da representação baseada numa congruência óptica entre as qualidades pictóricas da imagem e as qualidades visuais do objecto representado. $\mathrm{O}$ que redundaria, neste caso específico, numa indiferenciação entre visibilidade e visualidade. A ideia de um primado do visual nas nossas

27 Uma ideia que está já presente nos escritos de Leon Battista Alberti, quando descreve os elementos pictóricos que preenchem a superfície da imagem e a relação entre estes como signos. Alberti, Leon Battista, Della Pittura - Über die Malkunst, Hrsg. und übers. von Oskar Bätschmann und Sandra Gianfreda, Darmstadt, Wissenschaftliche Buchgesellschaft, 2. Auflage, 2007, pp. 66-67.

${ }^{28}$ Burke, Edmund, A philosophical inquiry into the origins of our ideas of the sublime and beautiful: with an introductory discourse concerning taste, Baltimore, William \& Joseph Neal, 1833, pp. 67-72. 
culturas resulta, em parte, de tal indiferenciação. Isto porque se parte do princípio, de que há uma continuidade natural entre aquilo que é visível na imagem - o objecto representante - e aquilo que pode ser visualizado através da representação - o objecto representado. O que nos levaria a ver na imagem quer a capacidade de despertar uma pretensa imediaticidade originária da nossa percepção - as teorias do "olhar inocente" - quer, por outro lado, a capacidade de fomentar uma relação osmótica entre real e imaginário.

Tal ideia está presente na óptica ecológica de James J. Gibson. Gibson estabelece uma distinção entre imagem e palavra, baseada no critério de denotação: um objecto representado por um nome e um objecto representado por uma imagem. Na sua opinião, o objecto e o nome têm uma «relação extrínseca» (extrinsic relation); e o objecto e a imagem, pelo contrário, uma «relação intrínseca» (intrinsic relation). ${ }^{29}$ A percepção imagética aproxima-se da percepção não-convencional, não estando, por isso, sujeita a mediação verbal, já que ela não requer uma grande capacidade de associação mental, como no caso do discurso, mas antes permite uma síntese das informações ópticas que são comuns ou semelhantes ao objecto e à imagem. ${ }^{30}$ Ernst Gombrich, e apesar de se insurgir contra a ideia de um olhar inocente, vai utilizar muitas das formulações de Gibson para sustentar a sua teoria da ilusão: a imagem consegue "iludir" a nossa percepção, mais concretamente, o objecto bidimensional da imagem transforma-se em objecto tridimensional. ${ }^{31}$ Gombrich, seguindo os modelos cognitivos de uma óptica ecológica, concebe um hiato entre percepção e mediação. Este hiato, tal como acontece nas teorias da semelhança, surge graças a uma simetria mental entre imagem e objecto representado.

Com efeito, o facto de poder haver modelos cognitivos invariáveis, como defende Gibson na sua óptica ecológica, não põe em causa uma óptica da percepção cultural. Pelo contrário. O problema de uma óptica ecológica reside na ideia de que a relação entre imagem e percepção não está sujeita a aprendizagem, pressupondo-se, dessa forma, que os modelos

${ }^{29}$ Gibson, James J., A theory of pictorial perception, in: Audio-Visual Communication Review, 1954, pp. 3-23, p. 11.

${ }^{30}$ Idêntica posição é defendida pelo neurobiólogo Wolf Singer. Para o cientista alemão, a imagem aproxima-se mais de uma percepção pouco articulada, isto é, de uma percepção que funciona independentemente dos códigos simbólicos da linguagem. A distância que a imagem não consegue criar em ralação à percepção é, segundo Singer, alcançada pela linguagem. Singer, Wolf, Das Bild in uns - Vom Bild zur Wahrnehmung, In: Iconic Turn. Die neue Macht der Bilder, Hrsg. von Christa Maar und Hubert Burda, Köln, Dumont, 2004, pp. 56-76, pp. 56-57. 
invariáveis não dependem do modo como a imagem é vista e compreendida nem da nossa experiência com imagens. Ou seja, as nossas experiências com imagens - o nosso "passado imagético"- não modificariam nem solidificariam os modos de ver, já que a similaridade entre imagem e objecto representado seria capaz de criar uma transparência cognitiva que não estaria sujeita aos processos de mediação.

Uma imagem que representa um objecto ou uma cena não nos devolve, por extensão, a visibilidade do objecto ou da cena representados. Tal visibilidade - inerente às propriedades tridimensionais dos objectos no espaço - é suspensa pela superfície bidimensional da imagem a favor do seu próprio carácter visual. A imagem só se torna imagem e, por sua vez, configuração simbólica sensível, se ultrapassar essa congruência entre visibilidade e visualidade. (Esta passagem é aquilo que pode distinguir a imagem-símbolo da imagem-simulacrum, já que, em rigor, a última, na sua indiferença sensível em relação à representação, nunca chega a quebrar a congruência que mantém com o objecto que mostra. Pelo contrário - e daí também o facto de uma imagem-simulacrum não ser propriamente uma imagem $^{32}$-, tal indiferença é a condição necessária para que a mediação seja reduzida a simulação, ou melhor, para que a mediação seja suspensa.)

Não se trata aqui apenas de contra-argumentar com a fórmula de uma inversão da ordem da referência $-x$ pode estar para $y$, mas não $y$ para $x$ -, como a que Nelson Goodman utiliza para criticar as teorias da semelhança e sustentar a tese de um convencionalismo arbitrário dos critérios denotacionais. ${ }^{33}$ Duas imagens distintas, assim como dois objectos presentes na nossa vida quotidiana, podem partilhar semelhanças, tanto em relação ao tema da representação como em relação ao estilo pictórico que apresentam. Ora, já tal não se verifica com um objecto representado por uma imagem. Reconhecer numa fotografia, por exemplo, a representação de um rosto que nos é familiar não é uma mera herança filogenética, mas antes requer, tal como acontece com a articulação das formas discursivas, uma aprendizagem da relação simbólica que nos permite dizer que esse rosto fotografado é uma representação da pessoa que temos em mente. Jan Deregowski mostra-nos, precisamente, que, em certas sociedades, este processo de reconhecimento não é linear. Segundo o autor, há sociedades em que não existe uma consciência de imagem, sendo, por isso, impossível

31 Gombrich, E. H., Art and Illusion. A study in the psychology of pictorial representation, Oxford, Phaidon Press, 1990; Idem, The image and the eye. Further studies in the psychology of pictorial representation, Oxford, Phaidon Press, 1986.

32 Sobre isso, vide Seel, Martin, Ästhetik des Erscheinens, Frankfurt am Main, Suhrkamp Verlag, 2003, pp. 287-288.

33 Goodman, Nelson, op. cit. , pp. 15-17. 
para os seus membros identificar ou reconhecer objectos e pessoas através de símbolos imagéticos. Daí que Deregowski, ao colocar a questão sobre uma hipotética universalidade do reconhecimento através de imagens, defenda uma posição contrária, já que o "reconhecimento pictural" depende sempre de processos de aprendizagem. ${ }^{34}$

\section{Medialidade e materialidade}

O facto de a imagem ser um símbolo - e continuando a responder à questão da compatibilidade entre estruturas sensíveis e estruturas sígnicas - obriga-nos a encontrar já na sua própria materialidade um ponto de partida para se poder compreender os processos de mediação. Porém, tal parece não acontecer, quando se reduz a mediação a um mero processo entre imagem e significado. E nesse sentido, a ideia de uma pretensa transparência dos processos imagéticos não acompanha somente as teorias da semelhança. Ela surge também na semiótica, nomeadamente na relação entre imagem e significado. E ela surge, como convém aqui reiterar, porque entre imagem e significado há um primado da referência que relega a percepção e a materialidade do signo para um papel secundário. Muitas das vezes, tende-se a interpretar a imagem como uma configuração que apenas deriva de uma representação mental. A língua inglesa reserva-nos o termo image para as representações mentais e, por outro lado, o termo picture para as representações materiais. A questão coloca-se, como bem adverte Richard Wollheim, quando se supõe um pretenso primado da "image" sobre a "picture". ${ }^{35}$ Ou dito de outro modo: quando se pensa a representação sem a presença sensível do símbolo.

A inclusão do papel activo da percepção nos processos de mediação imagéticos nem sempre foi (nem continua a ser), como já vimos, uma exigência teórica assumida pela filosofia da imagem. Nesse sentido, há do ponto de vista teórico uma continuidade reiterada entre formas discursivas e formas imagéticas que, tanto em relação à esfera da percepção como em relação à esfera da materialidade, não é posta em causa - o melhor seria dizer, em diferença - tendo em conta a articulação específica de ambas. O conceito de representação estender-se-ia, por conseguinte, a ambas as formas, sem que este, contudo, implicasse uma redefinição do seu alcance perante a natureza medial que cada uma delas encerra. A passagem do material ao medial - aquilo que tece a natureza da articulação simbólica

${ }^{34}$ Deregowski, Jan B., Pictorial Perception and Culture, In: Image, Object, and Illusion, Scientific American, 1974, pp. 79-85, p. 79.

35 Wollheim, Richard, Art and its objects, Cambridge, Cambridge University Press, 2nd Edition, 1990, pp. 42-43. 
- assentaria única e exclusivamente nas estruturas endógenas da representação, sendo, dessa maneira, as estruturas materiais das configurações culturais remetidas para uma passividade instrumental - meios para fins -, não entrando nem influenciando directamente os processos de articulação.

No entanto, se se aceitar a premissa de que todas as configurações imagéticas requerem uma transformação dos seus substratos materiais em estruturas mediais, também se torna de igual forma plausível reconhecer o lugar efectivo que a materialidade ocupa nos processos de articulação. Esta passagem do material ao medial é um momento capital de qualquer articulação simbólica, sobretudo no que diz respeito à sua expressividade e à sua valência afectiva. Uma omissão do substrato material da imagem conduziria a uma perda da tensão imanente que existe quer na sua produção quer na sua recepção. $\mathrm{O}$ material não permite apenas a passagem ao medial. $\mathrm{O}$ material dá à forma a sua própria estrutura, ou como sintetiza Henri Focillon, «a matéria impõe a sua própria forma à forma». ${ }^{36} \mathrm{~A}$ forma é sempre o resultado de um processo de incorporação. Se por um lado, há um impulso sugestivo provocado pelos meios materiais, por outro, há uma resistência que se opõe à criação de quem concebe e mostra, bem como à articulação de quem vê. Henri Matisse diz-nos que a materialidade do medium - como por exemplo, as dimensões da superfície pictórica não possibilita apenas condições essenciais para a configuração sensível da imagem, como também impõe as suas estruturas à própria configuração. ${ }^{37}$ A expressão artística é feita através desse duplo trabalho do material: impulso e resistência. E Jackson Pollock, nos seus Drip Paintings, vai utilizar precisamente o impulso e a resistência dados pela materialidade da superfície pictórica para criar a sua técnica. O que o leva a dizer que, quando está a pintar uma tela, «não é consciente daquilo que faz», já que, ao ter um contacto mais próximo com a superfície pictórica, deixa de poder ter qualquer distância em relação ao processo criativo há aqui aquilo que ele designa de «congruência entre dar e receber», isto é, o material passa a ter um papel activo no próprio acto performativo e o pintor, nessa medida, acaba por "receber" simultaneamente a resistência da superfície material aos seus gestos configuradores. ${ }^{38}$

${ }^{36}$ Focillon, Henri, Vie des Formes, Paris, Presses Universitaires de France, 1947, p. 52.

${ }^{37}$ Matisse, Henri, Écrits et propos sur l'art, Texte, notes et index établis par Dominique Fourcade, Paris, Hermann, 2005, p. 43.

38 Pollock, Jackson, My Painting, In: American Artists on Art. From 1940 to 1980, Edited by Ellen H. Johnson, New York, Icon Editions, 1982, p. 4. Mark Rothko, um dos fundadores do expressionismo abstracto, encontra também nas dimensões materiais da 
Esta dinâmica da materialidade - impulso e resistência, segundo a nossa síntese - é, por sua vez, uma condição fundamental para a dinâmica cultural dos processos de simbolização imagéticos, acabando por se espelhar na própria forma. Sem este duplo trabalho da materialidade nas configurações imagéticas, ser-nos-ia mais difícil distinguir a representação na imagem da presença da imagem. ${ }^{39}$ Nesse sentido, a materialidade acciona e acompanha já a nossa consciência dos processos de simbolização - na sua forma elementar, a diferença entre símbolo e simbolizado.

\section{Materialidade e articulabilidade}

A questão da materialidade reflecte-se igualmente no carácter espácio-temporal que a imagem assume quando articulada. A tese que desde o Laokoon de Gotthold Ephraim Lessing acabou por se tornar paradigma, remete a imagem - a pintura - para o domínio de uma percepção dada no espaço, articulada segundo uma ordem simultânea, sendo, por sua vez, uma percepção dada no tempo, segundo uma ordem sucessiva, exclusiva das formas discursivas - a poesia. A distinção de Lessing - uma resposta crítica à célebre fórmula horaciana da ut pictura poesis - está assente principalmente na ideia de movimento: a pintura, designada como arte espacial, é incapaz de ilustrar ou sugerir o movimento inerente às formas poéticas. ${ }^{40}$ Tempo e espaço, discurso e imagem aparecem, deste modo, como formas antitéticas.

imagem uma relação específica entre obra e criador: «Pintar uma imagem pequena é colocarmo-nos fora da própria experiência de pintar». Daí que, segundo o pintor, as telas com maior dimensão sejam aquelas que tendem a oferecer ao artista uma maior proximidade que o coloca dentro da própria imagem. E, tal como Pollock, também partilha da ideia (e da experiência) de que o artista, quando confrontado com uma superfície pictórica grande, deixa de poder ter um controlo absoluto sobre os processos de configuração. Rothko, Mark, Writings on Art, Edited by Miguel López-Remiro, New Haven and London, Yale University Press, 2006, p. 74.

${ }^{39}$ Sobre a temática da materialidade e, mais precisamente, em relação à importância da moldura das superfícies pictóricas, vide, por exemplo, Simmel, Georg, Der Bilderrahmen. Ein ästhetischer Versuch, In: Aufsätze und Abhandlungen 1901-1908, Band I, Hrsg. von Rüdiger Kramme, Angela Rammstedt und Otthein Rammstedt, Frankfurt am Main, Suhrkamp Verlag, 1995, pp. 101-108; Schapiro, Meyer, On some Problems in the Semiotics of Visual Art: Field and Vehicle in Image-Signs, In: Theory and Philosophy of Art: Style, Artist, and Society, New York, George Braziller, 1994, pp. 1-32.

${ }^{40}$ Lessing, G. E., Laokoon: oder über die Grenzen der Malerei und Poesie, in: Laokoon, Briefe, antiquarischen Inhalts, Hrsg. von Wilfried Barner, Frankfurt am Main, Deutscher Klassiker Verlag, 2007, p. 116. 
Esta ideia traçada por Lessing é utilizada por Susanne Langer para estabelecer uma distinção entre formas discursivas e formas visuais. Langer, inspirada pelas obras de Ernst Cassirer e Alfred North Whitehead, reconhece que as formas visuais são providas de articulabilidade. No entanto, «as leis que governam esta articulabilidade são diferentes das da sintaxe que governam a linguagem. A diferença capital reside no facto de que as formas visuais não são discursivas. Elas não apresentam os seus elementos estruturantes sucessivamente, mas antes simultaneamente; razão essa por que é possível apreender as relações que determinam uma estrutura visual em um único acto de visão.» ${ }^{41}$ Apesar da distinção estabelecida, Langer também admite que uma grande parte das formas visuais pode ser articulada discursivamente, em particular todas as formas que se prestam a representações geométricas ou esquemáticas, pois estas «expressam factos para uma compreensão discursiva e o seu conteúdo, ao poder ser verbalizado, fica sujeito a leis de vocabulário e sintaxe.» ${ }^{42}$

Mas será que, como pretende Langer, nos é possível apreender uma imagem "em um único acto de visão"?

As formas espaciais não são antagónicas às formas temporais. Pelo contrário. Tempo e espaço dão à articulação das formas imagéticas e discursivas um carácter próprio. Por outro lado, e este é um dos momentos capitais que marca a nossa experiência quando iniciamos a leitura de um texto, as formas discursivas textuais requerem sempre uma configuração visual que nos permite transformar a espacialidade dos seus elementos gráficos numa ordem temporal sucessiva. Quando lido, contudo, a ordem espacial nunca se deixa reduzir plenamente à legibilidade do texto. O carácter fisionómico da configuração de um texto - o sentido da sua atmosfera gráfica - não é indiferente ao seu conteúdo. A atmosfera gráfica de um poema não é a mesma da de um texto com um perfil científico. Se a deste último alimenta o seu rigor conceptual, a sua objectividade interna, já a do primeiro tende a contribuir para a sua expressividade lírica, para a sua própria individualidade estética. Em Les deux vertus d'un livre, Paul

${ }^{41}$ Langer, Susanne, Philosophy in a New Key. A Study in the Symbolism of Reason, Rite, and Art, Cambridge, Massachusetts, Harvard University Press, 1957, p. 93. As formas visuais, ao contrário das discursivas, têm uma estrutura simbólica que lhes permite expressar conteúdos que não são articuláveis discursivamente. Langer nomeia esses conteúdos através do termo feeling; mas feeling não é aqui apenas sinónimo de sentimento ou de emoção: o termo remete para todos os conteúdos da percepção que não estão sujeitos à articulação discursiva. Ibidem, p. 87. Um aprofundamento destas teses de Langer encontra-se na sua obra Feeling and Form. A theory of art developed from Philosophy in a New Key, New York, Charles Scribner's Sons, 1953.

42 Idem, Philosophy in a New Key, p. 260. 
Valery mostra-nos que a legibilidade de um texto - «o texto lido» - é sempre acompanhada por «uma impressão total», por uma ordem «imediata e simultânea» dadas pela visualidade do texto - «o texto visto» - enquanto forma tipográfica. A cor negra dos caracteres e o fundo branco da página acabam por conferir ao texto um carácter imagético. Nesse sentido, e como sintetiza o escritor, «uma página é uma imagem». ${ }^{43}$

Com efeito, o facto de uma superfície pictórica possuir uma existência material dada no espaço, isso não pressupõe, contudo, que o carácter da sua articulação seja apenas marcado por uma ordem simultânea. A presença material de um medium - este quadro, esta estátua, como habitualmente dizemos - é animada e, com isso, transformada durante os processos de mediação. Tanto a observação de uma estátua como a de uma imagem, como bem reparou Friedrich Schleiermacher, requerem uma articulação sequencial, assim como a audição de um trecho musical, e pese embora a sua existência material ser dada no tempo, requer uma ordem simultânea através da qual nos é possível ter uma impressão conjunta das suas diferentes nuances. ${ }^{44}$ Para que uma imagem possa ser vista na sua totalidade, são precisas "mais fixações" das que um único olhar consegue abarcar. Estas "fixações" podem ser rápidas e, nesse aspecto, levar o observador a acreditar que, na verdade, ele percepciona a imagem em um único acto de visão. Mas, em rigor, não é aquilo que acontece. São estas sequências de fixações - fixações que apresentam diferentes nuances pictóricas - que, depois de articuladas e integradas, nos permitem ter uma visão global simultânea - da imagem. ${ }^{45}$ Deste modo, e sob proposta de definição, poder-se-á dizer que a simultaneidade é o resultado de um processo sequencial através do qual várias fixações sensíveis são parcialmente integradas.

Além disso, convém acrescentar aqui outros fundamentos que podem ilustrar melhor tal unidade entre tempo e espaço imagéticos. Refiro-me, mais concretamente, à estrutura iconográfica de certas obras. No caso de representações bidimensionais, como as da arte pictural, as modalidades do tempo mediam não só o próprio processo perceptivo, como podem também articular a própria estrutura iconográfica de obras com um perfil essencialmente narrativo. Luca Giuliani, na sua obra Bild und Mythos, mostra-nos claramente que muita da iconografia mitológica grega - como por exemplo, a dos vasos cerâmicos dos séculos VI e V - é governada

43 Valery, Paul, Les deux vertus d'un livre, In: Pièces sur l'art, Paris, Gallimard, 1962, pp. 17-24, pp. 17-19.

${ }^{44}$ Schleiermacher, Friedrich, Ästhetik (1819/1825), Über den Begriff der Kunst (1831/ 32), Hrsg. von Thomas Lehnerer, Hamburg, Felix Meiner Verlag, 1984, pp. 45-46.

45 Götz, Karl Otto, Götz, Karin, Probleme der Bildästhetik. Eine Einführung in die Grundlagen des anschaulichen Denkens, Düsseldorf, Concept Verlag, 1972, pp. 25-26. 
por uma "pregnância narrativa». ${ }^{46}$ Esta "pregnância" acentuaria mais o carácter discursivo da imagem em detrimento da sua natureza pictórica, já que os seus conteúdos serviriam formas de transmissão culturais com uma função mnemotécnica assente na oralidade. ${ }^{47}$ Por outro lado, temos o caso da "pintura de paisagem" que, na sua vertente mais clássica, apresenta uma configuração pictórica baseada numa complementaridade plástica entre unidade simultânea e separação sucessiva dos elementos que entram na composição iconográfica da imagem - um «conflito irresolúvel» entre espaço e tempo, como o caracteriza Max Imdahl na sua análise sobre algumas das obras de Domenichino, Claude Lorrain e Jan Frans van Bloemen. ${ }^{48}$ Outras afinidades entre imagem e linguagem, espaço e tempo podem ser também encontradas na pintura chinesa clássica, que é, na opinião de Herbert Read, «uma extensão da caligrafia chinesa», ${ }^{49}$ porque escrever e pintar teriam o mesmo valor performativo.

\section{Forma e configuração}

Ora, como nos mostrou precisamente esta análise da dimensao espáciotemporal, a relação entre formas imagéticas e formas discursivas tem de ser vista também a partir da relação entre medium e forma, e não apenas a partir dos modos de representação. O suporte material da imagem, como já tinhamos visto, não tem uma estrutura autotélica, mas antes aberta às formas da percepção. É por causa desta abertura que o medium pode ser configurado culturalmente e, nessa exacta medida, adquirir e determinar formas de sentido variáveis, isto é, não absolutas. Uma absolutização do medium reforçaria ainda mais a dicotomização clássica entre matéria e forma. Os suportes materiais da imagem não têm, por isso, uma função passiva, uma função indiferente à própria forma e aos mecanismos perceptivos. Desta ideia resultam duas considerações essenciais para os

${ }^{46}$ Giuliani, Luca, Bild und Mythos. Geschichte der Bilderzählung in der griechischen Kunst, München, Verlag C. H. Beck, 2003, p. 248.

${ }^{47}$ Ibidem, pp. 245-246. Sobre as questões da função mnemotécnica atribuída à imagem e da relação entre imagem e escrita, vide, por exemplo, o detalhado estudo sobre a iconografia medieval efectuado por Wenzel, Horst, Hören und Sehen, Schrift und Bild: Kultur und Gedächtnis im Mittelalter, München, C. H. Beck, 1995.

${ }^{48}$ Imdahl, Max, Baumstellung und Raumwirkung. Zu verwandten Landschaftsbildern von Domenichino, Claude Lorrain und Jan Frans van Bloemen, in: Zur Kunst der Tradition, Gesammelte Schriften, Band 2, Hrsg. von Gundolf Winter, Frankfurt am Main, Suhrkamp Verlag, 1996, pp. 280-326, p. 289.

${ }^{49}$ Read, Herbert, The meaning of art, Bungay/Suffolk, Penguin Books, 1949, p. 78. 
nossos próximos passos: (1) A questão da imagem, ao ser reduzida às modalidades de representação - imagem e objecto ou signo e significado -, deixa de poder incluir o papel activo da materialidade do medium nos processos de simbolização; (2) Se se aceitar a ideia da preponderância da materialidade, então fará sentido pensar a relação entre formas imagéticas e formas discursivas já a partir do modo como ambas se incorporam materialmente.

\subsection{Configuração e correspondência: o ver através da imagem}

A passagem do material ao medial - através da qual, na verdade, forma e matéria, imagem e medium se fundem simbolicamente - revela características distintas, dependendo das formas simbólicas a que as configurações imagéticas estão ligadas. Sem que seja aqui o lugar para podermos enunciar e caracterizar todas essas formas, bem como a relação que mantém com a imagem, podemos, no entanto, estabelecer uma diferença teórica que envolve a natureza material da maior parte das formas de mediação. Refiro-me, mais concretamente, ao carácter da sua articulação, cujo perfil pode ser traçado do seguinte modo: configurações imagéticas que implicam uma articulação simbólica marcada pela correspondência ${ }^{50}$ como por exemplo, aquelas utilizadas pela ciência, técnica, meios de informação, formas publicitárias - apresentam um maior grau de contingência em relação à materialidade sensível que lhes dá suporte.

As configurações imagéticas que possuem um perfil de correspondência podem ser reproduzidas em vários e diferentes suportes materiais. $\mathrm{O}$ seu substrato material é variável, isto é, uma imagem, como por exemplo, a imagem esquemática de uma experiência científica, pode ser reproduzida independentemente do medium de reprodução utilizado, sem que com isso haja uma mudança do seu sentido. Esta relação contingente entre forma e medium é um dos factos que mais contribui para que haja uma aproximação das formas imagéticas de correspondência às formas discursivas. Tal como um texto, também estas podem ser reproduzidas e, nessa exacta medida, verbalizadas.

Comum a estas formas imagéticas com perfil de correspondência é a relação basilar que fomentam entre mediação e percepção. Embora não tendo todas a mesma estrutura de representação, partilham entre si do modo como a própria dinâmica da visualidade é assegurada. Dinâmica essa

50 Com o termo "correspondência", pretende-se nomear a relação entre símbolo e simbolizado cuja forma, ao não depender da individualidade física do primeiro, torna possível a reprodução e transmissão do segundo. 
que pressupõe uma relação circular entre imagem e objecto representado, pois estamos perante processos de mediação que exigem um maior grau de referencialidade, não sendo esta, contudo, exclusiva da esfera denotativa - ou seja, a referencialidade não pressupõe que haja sempre um objecto com uma extensão real; objectos imaginários podem ser, de igual modo, articulados. Por isso, o conceito de "correspondência" sugere-nos a ideia de um ver através. Este ver através - cuja natureza, porém, não implica necessariamente uma consciência de imagem, como acontece no caso do olhar mítico ou mitificado - pressupõe uma articulabilidade que se não limita às estruturas pictóricas que formam materialmente a configuração da imagem. A multiplicidade semântica que através desta é articulada dá-se de forma contingente em relação às suas estruturas sígnicas internas, já que estas não possuem uma autonomia imagética, mas antes dependem dos objectos que representam. A imagem, ao remeter para algo que está fora de si, submete-se à contingência das estruturas sígnicas externas. E isso implica que a individualidade física da imagem seja, por assim dizer, suspensa a favor da sua articulabilidade simbólica.

Tal empobrecimento do substracto sensível da imagem é, muitas das vezes, feito em plena concordância com critérios discursivos. O esquematismo das formas imagéticas científicas - apesar de estas poderem assumir várias nuances pictóricas ou cinemáticas baseadas em critérios estéticos de selecção e configuração ${ }^{51}$ - assenta em lógicas de articulação alfanuméricas cuja aplicabilidade teórico-prática não está dependente dos elementos sensíveis que suportam materialmente a articulação. A linearidade convencional que a imagem na ciência sofre é, nesse aspecto, o resultado inevitável dessa esquematização. O mesmo é dizer: tal linearidade pode ser vista, neste caso, como forma tornada sensível da "economia do olhar" científico. ${ }^{52}$

\subsection{Configuração e imanência: a inversão dos processos de simbolização}

Compreender a redução do pictórico operada pelas configurações imagéticas que possuem um perfil de correspondência é, nessa medida, uma tarefa teórica que exige critérios de diferenciação cuja normatividade só

51 Sobre isto, vide Kemp, Martin, Bilderwissen. Die Anschaulichkeit naturwissenschaftlicher Phänomene, Übers. von Jürgen Blasius, Köln, Dumont Verlag, 2003.

52 Uma explicação técnica dos processos de mediação imagéticos na ciência pode ser encontrada em Beyer, Andreas, Lohoff, Markus (Hrsg.), Bild und Erkenntnis. Formen und Funktionen des Bildes in Wissenschaft und Technik, München/Berlin, Deutscher Kunstverlag, 2005. 
pode ser entendida a partir da emancipação das formas culturais propriamente artísticas. Compreender é, nesse sentido, colocar a arte como referência normativa, mais especificamente, a autonomia estética de que gozam as configurações imagéticas artísticas. Com efeito, se se entender a imagem como obra de arte - quer na sua produção quer na sua recepção - como o momento capital em que a imagem se afirma e consolida culturalmente segundo a sua idiossincrasia estética, a sua individualidade física e a sua abertura interpretativa, então fará sentido ver nesse mesmo momento uma evocação normativa daquilo que tece a diferença específica da imagem. Tal normatividade não nos aproxima apenas de uma ordem estética, mas já, de igual modo, de uma ordem ética que envolve a própria autonomização da arte como forma simbólica.

Coloquemos, então, a pergunta: qual é a diferença específica que a imagem, interpretada como obra de arte, impõe aos processos de simbolização?

A arte vem pôr em causa o perfil de correspondência das formas imagéticas. As estruturas sígnicas internas da imagem são aquelas que, acima de tudo, ditam a sua idiossincrasia estética e, com isso, a sua diferença como obra de arte. Mesmo no chamado "realismo" - expressão que, na verdade, manifesta mais um convencionalismo iconográfico do que propriamente uma visão assente na própria percepção humana - há elementos pictóricos que não se deixam submeter a uma estética de correspondência. Os elementos pictóricos que tecem a materialidade das formas imagéticas artísticas são elementos constitutivos dos processos de produção e recepção, não estando, por isso, sujeitos à mesma contingência configurativa que marca os processos relativos às formas imagéticas convencionais. Por outro lado, as formas imagéticas propriamente estéticas não são reproduzíveis. Forma e medium criam uma unidade estética, ou, como bem repara Niklas Luhmann, o medium torna-se forma..$^{53}$

Como presença individual que é, a imagem como obra de arte cria uma nova relação espácio-temporal com os contextos de exibição (museus, galerias etc.) que lhe permite, por sua vez, assegurar e acentuar a sua idiossincrasia física como objecto concreto perante a materialidade de objectos não-artísticos. A individualidade física da imagem marca, por assim dizer, uma discontinuidade material em relação aos elementos sensíveis que lhe são exteriores. Esta discontinuidade material não pode

${ }^{53}$ Luhmann, Niklas, Die Kunst der Gesellschaft, Frankfurt am Main, Suhrkamp Verlag, 1997, p. 176. No caso do cinema, como nos diz Walter Benjamin, a reprodução faz parte da própria natureza técnica do medium. Benjamin, W. , Das Kunstwerk im Zeitalter seiner technischen Reproduzierbarkeit, in: Medienästhetische Schriften, Ausw. von Detlev Schöttker, Frankfurt am Main, Suhrkamp Verlag, 2002, pp. 351-383, p. 359. 
ser experienciada fora dos contextos de exibição, nomeadamente quando a imagem é separada dos seus suportes materiais e, por motivos de reprodução, se dá a ver "através" de um medium (livro, catálogo, meios electrónicos etc.) que não o seu medium de origem.

É neste sentido que a reprodução impõe à obra de arte um perfil de correspondência - um ver através - que caracteriza as formas imagéticas convencionais; isto, claro está, se não dissociarmos, como bem defende Walter Benjamin, a experiência estética mediada pela reprodução da mediada pela obra de origem. Não estou com isto a dizer que tal individualidade deve ser apenas situada num "aqui" e "agora" dados por uma pretensa "aura" da obra de arte. A preocupação de Benjamin é assaz legítima. Ela insere-se num pressuposto epistemológico - com um cariz histórico-cultural - de não criar um hiato intransponível entre mediação e percepção, representação e presença. No entanto, um "presentismo" espacial e temporal não assegura ainda nem a individualidade física nem a natureza expressiva da imagem como obra de arte. Por outro lado, uma aproximação histórico-cultural ao conceito de obra requer igualmente que as estruturas da percepção sejam interpretadas, tendo em conta a sua articulação cultural. $\mathrm{O}$ misticismo que envolve o presentismo aurático resulta, em parte, de uma categorização do espaço e tempo como formas puras da razão. A questão da reprodutividade técnica não vem pôr em causa per se a individualidade física da imagem. A reprodução não pode ser vista apenas a partir do seu lado técnico, mas também já a partir do seu lado simbólico - isto é, a partir da reprodução do sentido. Ao aumentar a complexidade discursiva em torno da obra fragmentada em imagens, a reprodução tende, por outro lado, a enfraquecer a complexidade pictórica que lhe é inerente. ${ }^{54}$

Dentro de uma lógica semiótica, a articulação entre signo e significado ganha na arte um novo perfil simbólico que se distingue radicalmente daquele que é dado pelas formas imagéticas convencionais: a imagem como obra de arte vem inaugurar uma relação de imanência entre signo e significado, entre materialidade e sentido. O "ver através da imagem", típico das formas convencionais, dá lugar a um "ver a imagem na imagem", a uma forma de ver que ultrapassa os limites impostos pelas lógicas de correspondência e

54 Uma posição contrária a esta encontra-se, por exemplo, em Ullrich, Wolfgang, Raffinierte Kunst. Übung vor Reproduktionen, Berlin, Verlag Klaus Wagenbach, 2009. Para Ullrich, a reprodução acaba por contribuir para o aperfeiçoamento da obra, dando-lhe um carácter estético que lhe faltava inicialmente. O estético, assim interpretado, remete para um idealismo da forma, em detrimento do papel constitutivo do medium material. 
que, nesse sentido, é capaz de articular a imagem em função da imagem e não em função de uma referencialidade exógena.

É por causa dessa inversão das lógicas de simbolização convencionais ${ }^{55}$ que a imagem, interpretada como obra de arte, se revela capaz de impor um regresso à esfera do sensível. A imanência que caracteriza o seu perfil simbólico faz com que ela se dê e, ao mesmo tempo, se negue como símbolo, já que este, ao ser interpretado segundo a sua abertura estética, não se deixa reduzir aos processos de significacão. $\mathrm{O}$ signo estético não se esgota com o significado, mas antes se multiplica como significado. Esta paradoxalidade sígnica das formas artísticas é um dos factores que, segundo Susanne Langer, mais contribui para a complexidade da obra de arte. Ao não poderem ser «abstraídas das obras que as exibem», as formas artísticas criam uma «congruência» tão estreita entre símbolo e simbolizado, ao ponto de ambos se darem «como uma única realidade».56 A redução da distância entre símbolo e simbolizado operada pela arte, e ao invés daquela que marca o olhar mítico, materializa-se, por sua vez, em reflexão e consciência, diferença e sentido. ${ }^{57}$

\subsection{Visualidade e legibilidade: a conversão textual da imagem}

Já o contrário tende a acontecer com as formas imagéticas convencionais: o signo é subtraído pela significação. Há, como já tínhamos visto, uma certa proximidade entre a articulabilidade das formas imagéticas convencionais e a das formas discursivas. Tal proximidade não se dá

55 Sobre esta inversão simbólica operada pela arte, vide Schwemmer, Oswald, Kulturphilosophie. Eine medientheoretische Grundlegung, München, Wilhelm Fink Verlag, 2005, pp. 157-200.

${ }^{56}$ Langer, Susanne, Problems of art, London, Routledge \& Kegan Paul, 1957, pp. 25 -26. A inversão simbólica criada pela arte é, por outro lado, uma possibilidade que sustenta não só a sua auto-reflexividade, mas também a reflexividade sobre os próprios processos de simbolização culturais. Este é um dos factores que mais contribui para que a arte possa ser considerada uma forma de conhecimento.

57 Podemos ver nessa redução consciente a possibilidade de a obra de arte contribuir culturalmente para a redução de complexidade social. Da individualidade física da imagem como obra de arte advém, por assim dizer, uma autêntica pedagogia do sensível, isto é, uma forma de consciência de presença que, aplicada a outras formas culturais, como a linguagem, se torna indispensável para preparar e solidificar mecanismos de concentração, expressão e criatividade. Sobre esta temática, vide Read, Herbert, Education through Art, In: Selected Writings of Herbert Read, London, Faber and Faber, 1963, pp. 361-375; Idem, Icon and Idea. The Function of Art in the Development of Human Consciousness, London, Faber and Faber, 1955. 
apenas através de lógicas de representação comuns, mas resulta igualmente de a imagem como símbolo sensível que é, perder a sua individualidade física e passar a ser articulada materialmente segundo modelos sígnicos próximos dos da linguagem. A evolução da linguagem escrita e falada mostra-nos, precisamente, o processo inverso: a linguagem teve de perder ou enfraquecer a sua génese imagética para se constituir como forma simbólica autónoma; o signo teve de perder os seus traços pictográficos e ideográficos - o signo-imagem - para se estabelecer como signo-palavra. A linearização da linguagem escrita, embora tenha contribuído para uma «unificação do processo expressivo», contribuiu, por outro lado, para um «empobrecimento» da expressividade imagética do símbolo. ${ }^{58}$

A relação de contiguidade entre imagem e palavra, como é visível, por exemplo, nas formas publicitárias, tende a empobrecer a natureza visual do imagético já na sua configuração sensível, isto é, a configuração sensível da imagem é reduzida a uma funcionalidade informativa. A imagem passa a ter uma articulação esquemática. E é esta articulação, por sua vez, que lhe permite tornar-se legível e dar-se como discurso. A visualidade da imagem, ao perder as suas dimensões propriamente imagéticas, transforma-se, pois, na legibilidade do signo. Nesse sentido, podemos falar aqui de a formação de uma complexidade não-imagética, já que as modalidades sígnicas internas da imagem passam a ser articuladas em função de uma referencialidade externa. É esse carácter de legibilidade que, em muitos casos, determina os focos de atenção visual e, consequentemente, o próprio campo visual. Uma visualidade articulada pela legibilidade faz com que a imagem perca a sua relevância sensível. A imagem, na sua metamorfose em signo discursivo, ganha uma configuração esquemática, perdendo assim a sua configuração pictórica.

Um dos melhores exemplos que ilustra tal empobrecimento do imagético pode ser encontrado nas tecnologias da virtualidade. Estas vêm colocar, antes de tudo, a questão da transformação da materialidade do medium tradicional, antes de colocar propriamente as questões relativas aos conteúdos mediados. As estruturas do medium tradicional sofrem um processo de hibridização. O computador, por exemplo, passa a ser o medium através do qual todas a formas - imagéticas e discursivas - são configuradas virtualmente. Desta configuração indiferenciada, resulta uma nova relação entre visualidade e textualidade, imagem e palavra: o imagético é submetido a uma conversão textual. Trata-se, na verdade, de um processo de conversão que implica uma configuração triádica. No caso

${ }^{58}$ Leroi-Gourhan, André, Le geste et la parole. I. Technique et langage, Paris, Éditions Albin Michel, 1964, p. 293. 
da conversão textual de uma imagem, essa tríade pode apresentar a seguinte ordem: imagem-texto-imagem. A imagem é mediada e filtrada pelas estruturas textuais.

Para além disso, e como já tínhamos visto, a articulação simbólica mostra-nos que os processos de mediação não podem ser pensados sem a inclusão do papel activo da percepção. Se se aplicar este pressuposto às novas formas imagéticas, em particular àquelas utilizadas pelos mass media, torna-se-á claro que há uma maior tensão entre mediação e percepção - o que nalguns casos, como em determinadas sequências cinemáticas publicitárias, redunda mesmo em conflito. O que esta tensão nos mostra é, principalmente, um primado da mediação sobre os mecanismos e processos perceptivos, dado estes não conseguirem articular os conteúdos visuais expressos pela imagem. Há aqui um desfasamento entre mediação e percepção. Na impossibilidade de os conteúdos serem articulados, as emoções que daí resultam aproximam-se mais de verdadeiras reacções do que propriamente de respostas conscientes a sugestões informativas. Sequências imagéticas cinemáticas - como as de um filme publicitário que têm um perfil de correspondência são, em muitos casos, apenas percepcionáveis graças a uma estrutura discursiva que acompanha a articulação sequencial das imagens. A ordem discursiva articula aquilo que, em rigor, nunca se torna visível para o espectador - o sentido da articulação passa, por conseguinte, a não implicar uma correspondência directa em relação ao próprio visual. O conteúdo da informação é acentuado, ao mesmo tempo que a imageticidade da forma é enfraquecida.

\section{Conclusão}

Em suma, e como tínhamos procurado fundamentar, o mito do "poder da imagem" resulta, em grande parte, de uma absolutização das características que distinguem as formas imagéticas das formas discursivas. Um primado do imagético, não correspondendo necessariamente a uma ascensão das formas visuais, seria, nessa medida, plausível, se houvesse nas nossas sociedades uma consciência de imagem governada pelas formas artísticas. (O que exigiria, da mesma maneira, que a arte, na sua idealidade e na sua praxis, pudesse fazer jus à diferença que a distingue das outras formas culturais.) A filosofia da imagem, ainda que seja uma disciplina jovem, é uma disciplina fundamental para contribuir para essa consciência. E da reflexão que aqui se apresentou resulta, pelo menos, um fundamento importante para uma filosofia da imagem: as formas imagéticas não podem ser única e exclusivamente interpretadas a partir de uma mera visão semiológica dos processos de mediação; elas têm de ser interpretadas já 
a partir das estruturas materiais que lhe são inerentes, dado que se não há alteridade sem medialidade, não pode haver também medialidade (nem consciência dela) sem materialidade. Por outro lado, é tarefa de uma filosofia da imagem a reflexão quer das lógicas culturais que envolvem processos discursivos e imagéticos quer do estatuto propriamente estético e artístico da imagem; sendo, nessa exacta medida, a história da arte uma disciplina indispensável para que esse estatuto possa ser cultural e historicamente fundamentado. 